\title{
Escaping the interpersonal power game: Online shopping in China
}

For citation:

Tian, Xiaoli (2018). "Escaping the interpersonal power game: Online shopping in China." Qualitative Sociology 41(4): 545-568.

\footnotetext{
Abstract:

The increasing popularity of online shopping is now a global phenomenon, and China has become the largest internet market in the world. The reasons behind this preference for online shopping are examined in this study through 63 in-depth interviews and 5 years of virtual ethnography of a major online shopping website in China called Taobao.com. Chinese customers prefer Taobao not only because of price and convenience, but also because they enjoy the interactional process, during which they obtain more information, feel less pressured to put on a status performance in comparison to physical stores, and pay less affective labor. Chinese customers tend to believe that interaction with sales clerks in physical shops is a burden, and try to avoid this form of contact. This is related to the fact that consensus on status hierarchy is still yet to be established in a society that is undergoing rapid transition. Consequently, online shopping entails social interaction that attributes more power, autonomy and freedom to customers than otherwise possible in brick-and-mortar shopping. This study shows how both the online interactional environments afforded by technology and the broader social contexts (the service quality and related aspects of status competition among different social groups in contemporary China) affect interpersonal interaction.
} 
Key words: online shopping; symbolic interaction; power dynamics; status competition; consumption; China

\section{Introduction}

Globally, the past decade has witnessed the rapid expansion of e-commerce (Lissitsa and Kol 2016; Horrigan 2008), with China as one of the fastest growing internet markets (The United Nations Conference of Trade and Development 2015). At the end of December 2016, 467 million Chinese were shopping online, which makes China the largest internet market in the world (CNNIC 2017) ${ }^{1}$. The largest shopping website in the country is Taobao (http://www.taobao.com). Taobao accounted for 80 percent of the total market share in 2014 while it took up 95\% of the market share in the (customer-to-customer) e-commerce market in 2014. ${ }^{2}$ In 2016 alone, Chinese consumers spent 101.1 billion RMB on Taobao (Alibaba Group 2016).

Existing studies, mainly conducted by economists, claim that this massive increase in online shopping is due to price and convenience; consumers are always searching for the lowest price or most highly reputed product at their own freedom, which offset the risks of online shopping (Guo and Jaafar 2011; Su and Huang 2011; Han 2007; Koyuncu and Bhattacharya 2004; Yoon 2009; Liu et al. 2008). However, economic rationality cannot explain many online shopping behaviors. Moreover, while Alibaba ${ }^{3}$, the company owner of Taobao, alleges that

\footnotetext{
${ }^{1}$ Annual active consumers on Alibaba's China retail marketplaces reached 515 million, an increase of 27 million from the 12-month period ended September 30, 2017 (Alibaba Group, 2018).

${ }^{2}$ https://www.forbes.com/sites/greatspeculations/2014/12/02/heres-why-changing-market-dynamics-should-worryalibabas-investors/\#7ce2f6ef43e3

${ }^{3}$ Alibaba annual report http://ar.alibabagroup.com/2015/assets/pdf/20-F.PDF
} 
factors like a wide selection, competitive prices, and convenient payment improve the shopping experience of Taobao customers, it is still unclear as to why online shopping is considered convenient. The merchandise is not made tangible, nor is there the convenience of obtaining the purchased items immediately. So, what exactly does "convenience" mean to Chinese customers?

This paper deciphers online shopping behaviors in China. Indeed, online shoppers are participating in the economic activity of consuming, but also interacting with others, such as online sales staff. How are these social interactions different from those in conventional retail environments? How do they influence online purchasing behavior?

Based on 63 in-depth interviews and 5 years of online ethnography, I argue that online shopping entails social interaction that attributes more power, freedom and autonomy to customers than would otherwise be possible in brick-and-mortar shopping. Customers frequent Taobao not just to purchase necessary items but also to enjoy a form of shopping that entails a lower interaction cost. Online shopping is particularly attractive because, in contemporary China, the quality of service in brick-and-mortar stores is usually unpredictable. Chinese customers, usually urbanites, tend to view salespeople in offline shops as poorly trained migrant workers from rural areas. However, for reasons that will become clear, these salespeople are reluctant to assume subordinate roles when interacting with customers. Consumers and salespeople therefore lack consensus on status hierarchy, which increases the stress and anxiety of the customers. This lack of consensus is a feature of contemporary Chinese society as China rapidly transitions from a socialist state to a market economy (Nee and Opper 2012). This paper unravels how the lack of consensus on the social hierarchy influences economic activities such as the preference for online purchases. In so doing, I show how symbolic interaction perspectives can contribute to understanding power relations and conflict between different social groups. 


\section{The Sociology of Sales and Shopping as Social Interaction}

Economic sociologists have long indicated that economic activities such as selling and buying are embedded in social and cultural contexts (Granovetter 1973; Knorr-Cetina 2005). According to economic rationality, sales encounters focus on quality and price. Yet empirical research has found that shopping is a social practice situated in spatial and material contexts. Darr and Pinch (2013) revealed that economic actions in markets, such as making a purchase or sale, cannot be reduced to a stylized and abstract exchange. Instead, these actions are embedded in the material and social organization of the sales encounter. In particular, social obligations (or "an escalating scale of obligation") during sales encounters allows sellers and buyers to move from one stage to the next, and consequently enable completion of the transaction. The defining feature of selling and buying is the situated constitution of social obligation, which is achieved through the performances of the sellers and buyers on the sales floor (Darr and Pinch 2013). Moreover, social factors, such as time constraints, influence whether people incorporate ethical concerns into everyday shopping (Schoolman 2016).

Shopping is also a social process during which customers interact with salespeople (Stone 1954; Zukin and Maguire 2004). Interaction with sales clerks is inevitable in physical stores, which Goffman (1969:3-81) depicted as a prototypical case in his study on public interactions with strangers. Customers and sales personnel often convey personal information during the interaction. They act out personal aspects of their identity and morality during their sales performance (Darr and Pinch 2013). Even when purchasing expensive items such as real estate, the preferences and consumption decisions of consumers are influenced by the situational structuring of the sales agents (Besbris 2016). 
The existing literature (mostly research on Western contexts) usually emphasizes the positive value of face-to-face (FTF) interaction between customers and sales clerks. The desire for social interaction is one of the major motivations for shopping (Rohm and Swaminathan 2004). FTF interaction is considered a form of social support or a substitute for social support, and it provides important related benefits such as friendship, especially for vulnerable social groups (Kang and Ridgway 1996). For example, ethical customers support the Fair Trade Movement largely because of the solidarity produced by FTF interactions between consumers and producers (Brown 2011).

Shopping also occurs between people of different social categories. Status indicators influence shopping experiences, such as formal and informal presumptions of "whiteness" and class shape the behavior of both clerks and customers (Feagin and Sikes 1995; Williams 2005). While store clerks discriminate against customers, the reverse also holds true. According to earlier research in the U.S., white customers are more courteous to white workers than racialized service workers (Wrigley 1995). Other than race, status symbols are also important during interactions between anonymous individuals in urban settings (Simmel 1950) because they are the only means for others to "place and appraise one another" (Form and Stone 1957). As such, appearance often becomes more important than reputation because "status may be temporarily appropriated by the 'correct' display and manipulation of symbols" (Form and Stone 1957).

In sum, existing research has pointed out how shopping is a social process that is influenced by and reflects the existing social structure in society. However, even though online shopping is popular worldwide, there is a dearth of research on online shopping. Since China has become globally the largest shopping market, a study on its online shopping characteristics is 
timely and particularly interesting because competition for status and the lack of consensus on social hierarchy have caused day-to-day interpersonal conflicts — which is the focus of this study.

\section{Status Competition: Online and Offline}

Status concerns are fundamental in human motives and social life (Podolny 2005; Ridgeway et al. 2009; Tyler and Blader 2003). When social actors congregate, a status hierarchy usually emerges in which some are afforded higher esteem and social worth (Blau 1964; Emerson 1962; Homans 1961), and enjoy benefits imparted by their lower-status counterparts in social interactions (Fiske 2010).

Status competition involves people from different social groups. Conflict approaches emphasize competition between social groups for limited resources (Honneth 1996). Wealthy and powerful groups try to perpetuate privilege by suppressing the poor and powerless. Also, as sociologists have long noticed, social inequality is regulated by consensus on values by society members (Parsons 1940) or through a dominant ideology (Marx and Engels 1932/1998). That is, a status hierarchy is not only recognized and supported by high-status actors who benefit from their position, but also by lower status actors who do not benefit or even suffer because of the hierarchy (see, for example, Sutphin and Simpson 2009; Hahl and Zuckerman 2014).

However, even if a status hierarchy is embraced by the subordinate groups, there are still many social situations in which status is ambiguous, so that individuals enter into status competitions. These struggles at the individual and collective levels have been long recognized by sociologists (Park and Burgess 1924; Park 1925). Symbolic interactionists have traditionally attributed status inequality in interactions to external individual (e.g., age) or internal interaction (e.g., role of actors) factors, of which role is most relevant for determining the power relationships among interactants. In most settings, the roles are predetermined. Differentiated 
roles account for behaviors and expectations (Leifer 2000), which result in different levels of power and status of the participants involved. During participation in a social act, some manipulate the way social acts are constructed, while others end up in a subordinate position (Athens 2010). As Simmel (1950: 183) noted: "relationships of super-ordination and subordination play an immense role in social life".

Yet, sometimes status hierarchies are ambiguous. In many occasions, the cues of others are insufficient for determining who has a higher status. This is common in modern society, where there is frequent interaction with strangers, such as during service encounters. The common belief is that customers have a more powerful position. However, this is not even true in the West where this myth originated (Bolton and Houlihan 2005). Moreover, when societies are in social transition or have undergone such transition rapidly and transformed social norms, they have yet to establish a consensus on whom should be attributed with higher status and more respect. A typical example is China, since its economic reform in the past 40 years.

The struggle between power and inequality during interactions became more complex when the internet developed into a common means of social interaction. While computer-mediated communication could paradoxically traverse social boundaries, in reality, the boundaries remain (Zhao and Elesh 2008). Social inequality online prevails according to different dimensions. Gendered power differentials in communication style transcend the medium, for example (Sussman and Tyson 2000). Class also plays a role, since individuals with socioeconomically superior status are more likely to use the internet to strategically engage in so-called capitalenhancing activities online than the less privileged and therefore receive more payoff from internet use (Cho et al. 2003; Zillien and Hargittai 2009). Status also affects the ability to search for information online (Singh, Hansen, and Podolny 2010). 
New communication technologies have changed the spatial and temporal boundaries of social interaction, resulting in stark differences between online and offline social interactions. The major differences include: reliance on text rather than paralinguistic cues, which can cause problems during interpretation of meanings (Menchik and Tian 2008); context collapse (Davis and Jurgenson 2014); and an ambiguous audience (Tian and Menchik 2016; Tian 2017). Most obviously, appearance and manner delineate status and relationship in FTF interaction, but identification cannot be verified in many online contexts because of the differential availability of visual cues (Kalkhoff and Thye 2006; Kalkhoff, Younts, and Troyer 2008). Consequently, the internet is a liminal space that has reduced the effects of racial, gender, and sexual differences (Travers 2000).

To better understand how the online context has influenced interpersonal power dynamics, I focus on a particular set of participatory experiences, and argue that during online shopping, the mode of interaction between customers and online sales personnel differs from that which is conventionally found in brick-and-mortar shopping. In the latter, customers need to constantly defend their status and power with a status performance that demonstrates, for instance, their purchasing ability, while online customers feel more at ease and experience more freedom. This is particularly true in China, where many feel that physical stores offer poor service which results in stressful interactions. In contrast, online shopping reduces the process to a stylized and anonymous economic exchange due to the impact that the technological factors of online interaction have on status.

\section{Shopping in China: From Socialist Egalitarianism to Social Distinction}


A major feature that distinguishes China from Western developed societies is its rapid transformation in the past four decades. Since the market reform in 1978, consumption has taken precedence because it is a process where the Chinese, and especially the urban middle-class, can express themselves, pursue identity goals, and differentiate status (Yu 2014; Zhang 2017). Shopping as a social practice is not just to meet needs, but has become an endeavor that differentiates privilege and achieves social esteem. The social interactions involved in making purchases are a process that renders status differences intelligible and publicly visible (Hanser 2010).

However, the prominence of consumption is only a recent phenomenon. As such, it marks a radically different reality from life under socialist China, which was characterized by a planned economy where the personal needs of individuals were fulfilled by the work unit (or other forms of collectives) instead of exchanges in the market, and in which salespersons in state-run stores had no incentive to please their customers (Yu 2014).

Despite the rapid expansion of consumption and shopping malls in contemporary urban China, customers frequently complain about the quality of service, and these complaints are often echoed in traditional mass media and on social media (Yu 2014). Common complaints about service providers include their poor attitude and lack of respect, which could be attributed to Chinese cultural values, such as protecting face, conservatism and repayment of good/evil. These cultural values make it harder for Chinese service providers to treat customers with deference because they perceive the service role as requiring them to accord customers with status, and they are reluctant to do so with unfamiliar individuals (Johns, Chan and Yeung 2003). 
However, a major social factor that contributes to consumption narratives has been neglected: the majority of retail service positions in urban China are held by rural migrant workers. In contemporary China, millions of rural migrants leave for the cities every year to work and live. There were over 281.71 million migrant workers in China in 2016, and among them, $12.3 \%$ or over 34 million were working in the wholesale and retail industry. ${ }^{4}$ In contrast to factory or construction site workers, service industry workers have many more opportunities to interact with other people, especially local urbanites. This means that the local versus non-local, and urban versus rural statuses influence interpersonal interactions.

Scholars of stratification in China have pointed out the urban-rural divide (see for e.g., Wu and Treiman 2007), which is not only economically based (with an urban-rural income ratio as high as 3:1 [Whyte 2010]), but also culturally based: rural dwellers are discriminated in their daily social life for being poor, and urban dwellers scorn their lack of civility and value (Murphy 2004; Yi 2011). Therefore, urbanites attribute these migrant workers with a lower status due to three factors: first, the socioeconomic status of migrants is usually lower; second, they are rural and therefore have lower cultural capital; and third, they are providing direct services, which in the Chinese context, is usually perceived as low status work.

However, do these service providers accept status differentiation that attributes them with low status and low value? More particularly, how does the socialist past, such as the egalitarian discourse and the status attributed to workers and farmers, influence their understanding of the current situation? Scholars have rightly pointed out that the market economy of China has evolved from its socialist past and therefore cannot be understood independently of the historical

\footnotetext{
${ }^{4}$ http://www.stats.gov.cn/tjsj/zxfb/201704/t20170428_1489334.html.
} 
legacies of the socialist period (Walder 1996). In post-reform China, three distinct moral codes co-exist: the "yellow code", which is derived from Chinese traditional values, the "blue code" from Western and liberal values, and the "red code" from the revolutionary traditions of China, including the socialist period. In particular, the "red code" has been renewed and modernized by the Communist Party throughout the 1990s to the present to include Maoist collectivism and egalitarianism. Since this discourse is upheld by the state, it is diffused through official communication channels. Also, since the generation who lived through the socialist period is still very much alive, the legacy of socialist discourses is circulated through family memories (Palmer forthcoming). Most importantly, these "red code" discourses are often invoked in criticisms of current social conditions, especially during protests (Lee 2000). For example, workers of stateowned enterprise respond to substantial loss of status by drawing on the Maoist ideological tenet that " $(\mathrm{t})$ he worker is master". The socialist ideology and working-class culture established during the Maoist era are still important cultural repertoires for workers under market economy conditions. Therefore, although some of the elements of the socialist legacy, such as egalitarianism, glory of the laborer, "workers are the owners of the factories", and "farmers and workers are the masters of the country" contravene the ethos of the market economy and neoliberalism which is also promoted by the state, ordinary people, especially workers, still resort to such discourses or actuate them to defend their rights (Tong 2015). As Hoffman (2006) found, the post-socialist Chinese state still uses moral education, such as the Maoist era value of love for the nation, to cultivate patriotic professionalism in the young generation of university graduates. The continuity and resilience of the socialist legacy are often understudied but continue to mold contemporary social life. ${ }^{5}$ Therefore, I will show how the socialist legacy, such

\footnotetext{
${ }^{5}$ Recent research has pointed out that despite "everyone is equal" being only a myth during the socialist period in China (Yu 2014), people still tend to believe that egalitarianism existed at that time.
} 
as the emphasis on equal status, influences the shopping experience of contemporary Chinese urbanites in this study.

\section{Data and Method}

The data presented in this paper are part of a larger project on online shopping in China. The data collection took place from October 2011 to December 2016 and consisted of online ethnographic observations and in-depth interviews with customers, shop owners, and sales agents. Taobao was chosen as the field site because first, Taobao involves many small and individual customer-tocustomer vendors so that customers deal with many different owners and online sales agents, which differs from Amazon.com where all transactions are handled by Amazon itself. Second, Taobao was established in 2003 with a large number of long-running shops. This longevity makes it possible to observe whether shopping habits have changed over time. Third, Taobao has its own instant chat platform for the communication of all shops and customers called "Aliwangwang", which makes instant online interaction possible.

As the internet has become a very important part of everyday life, researchers have taken seriously the internet as a tool for research and use online ethnography (also called digital ethnography or virtual ethnography) to help understand various online and offline phenomenon (Garcia et al., 2009; Hallett and Barber 2014; Beneito-Montagut et al. 2017). While some researchers, especially those who study the new media, tend to focus only on online life and only do research online in the online community (Robinson and Schulz 2009), more and more research has begun to combine physical and digital data collection (Murthy 2008; Høybye 2016).

From 2011 to 2016, my online ethnography consisted of observing the online participants on Taobao engage in daily routine activities, such as stocking new inventory and commenting on 
purchases, and noting special events, such as the Singles' Day sales ${ }^{6}$ and end-of-the-year sales. I logged on to taobao.com and browsed on a daily basis, usually several times per day and on average, half an hour every day. After browsing for half a year, I identified fifteen Taobao shops that were used as the cases for more in-depth analyses. These Taobao shops sell items such as towels, electronics, and clothes. However, the majority (11 of the 15) specialized in selling apparel. I mostly focused on apparel shops and their clients because in contemporary China, especially in urban areas, apparel is a status symbol more than a necessity. I added these shops to my "favorite" list ${ }^{7}$ and every day I viewed the new items placed onto shelves, item descriptions provided by the shop owners or managers, new comments posted by customers, etc. In particular, I found that the Taobao stores all tended to provide detailed information on size. For example, they not only provided the width and length of the waist and sleeves for clothes, they also provided the size of different models and indicated whether an item was tightly or loosely fitting for the particular models. I also specifically examined the language used by customers and shop owners to determine whether they were trying to convey their status or a sense of authority or superiority. In doing so, I tried to find out if the website design leads to addictive online shopping. Unlike many other online ethnographic studies, such as those on newsgroups, the websites here are accessible to anyone, and therefore are intentionally and inherently "public" (Garcia et al. 2009).

I also observed the official Taobao forums and various chat groups of the regular customers/followers of the selected Taobao shops. On those forums, online shoppers shared their experience of shopping on Taobao in particular, and overall shopping experience in general.

\footnotetext{
${ }^{6}$ Launched by Alibaba in 2009, Singles' Day is November $11^{\text {th }}$ when products on Taobao are sold at discounted prices.

${ }^{7}$ Each Taobao customer can create a "my favorite store" list within the Taobao interface.
} 
They shared discount information, discussed the quality of products and service, showed off newly purchased items, and exchanged comments on online stores.

These online observations furthered my understanding of the norms and behavior patterns of the users, including online shoppers and sellers. Like Walstrom (2004a, 2004b), I participated as an ordinary customer by viewing, purchasing, and returning items from online shops. However, I refrained from commenting on any of the shop websites or chat groups, keeping in mind the rule of nonintervention during observation of the natural environment of the field (Garcia et al., 2009).

From the online observations and participation, I realized that merely doing online ethnography is insufficient because many of the activities of online shoppers cannot be solely explained by the data collected online. For example, during my online observations, I noticed that when customers are talking about services online, they usually refer to the logistics—if the vendor could ship the item within 24 hours, and how long delivery would take. Indeed, logistics efficiency is one of the central keys to the success of Taobao. In the past decade, the express delivery industry in China has grown rapidly in response to the demands of online shopping (Liang et al. 2016). However, when customers discussed the service in offline shops, they were referring to interpersonal interaction; that is, whether the salespersons have a good attitude and manners. Why is there such a different perception of "service"? While I have my own interpretations of why they do certain things based on the long-term online observations and by participating in online shopping as a regular customer myself, nevertheless, I needed concrete details on how they feel when they shop online and how it differs from shopping offline. 
Therefore, I decided to conduct offline FTF interviews with 48 customers, 5 shop owners, and 10 sales agents from August 2015 to April 2016. Their involvement originated from the online ethnography; I asked for volunteers to speak more in-depth about online shopping because I wanted to find out how online behaviors are affected by the context and situations within which the online users are situated. The aim was to obtain a more detailed understanding of the exact social and psychological factors that are at work when individuals decide whether to shop online and why. I asked about their experience of shopping in physical stores and compared how online shopping differs from shopping in physical stores and different settings. I focused on obtaining rich data on concrete, vividly-recalled shopping experiences. As for the shop owners and online salespersons, I focused on their strategies for communicating with customers. I also asked for descriptions of their tactics and behaviors as well as those that they had seen others use.

The interviews were conducted during several research trips to six cities in China: Beijing, Hangzhou, Shanghai, Changsha, Wuhan, and Guangzhou. I first sent interview requests to sellers and customers online, then scheduled interviews with those who readily agreed. For others who were hesitant, I chatted online with them first using Aliwangwang. The FTF interviews were conducted in places preferred by the respondents, such as coffee shops or university offices. Even though convenience sampling was used to recruit participants, I made sure that the customer respondents have diverse social backgrounds, with $60 \%$ women. The majority are urbanites with a monthly incomes ranging from 2,000 to 80,000 RMB, and ranging in age from their early 20 s to 60 s. Over half $(55 \%)$ are college educated. All indicated that they shopped both online and offline in the past 12 months. All interviews were conducted in Chinese, and quotes were translated into English by the author. 
The interviews did indeed reveal the perspectives of the participants on their shopping practices and experiences both online and offline. I then integrated their own interpretations, especially of their offline shopping experiences, into the larger study of their online behavior. The offline network of the participants, location in social spaces, and offline life and experiences thus added an invaluable triangulative function that helped me fully understand the online phenomenon. Even though online shopping is an activity that takes place primarily online, it cannot be explained by examining the online platform alone. Online shopping is closely related to the offline life of the online shoppers, such as social economic status, identity, and most importantly, offline shopping experience. Offline interviews enabled verification of information gathered online, understanding of why they buy online, more accurately determined their social status and self-identification, etc.

Indeed, the boundary between online and offline is often blurry (Hallett and Barber 2017, Garcia et al. 2009) because the internet has been so well integrated into everyday life. There is one social world that contains both online and offline sites of social activity. Online activities are not separate from other aspects of human actions and experiences, but rather a part of them (Garcia et al., 2009). Therefore, online activities need to be understood by re-locating the online users in their immediate offline network (see also Tian 2016; 2017). It also cannot be separated from the broader social context and even the historical legacy; that is, the culture of poor service quality in China, and the socialist legacy on egalitarian status among laborers, respectively.

Taken together, the in-depth interviews and online ethnography revealed a number of interaction processes in online shopping. I identified general trends and analyzed the cases in depth to understand the details of processes unknown before the start of the study, such as how customers interact with online sales personnel, or how they compare online and offline shopping. 
The different forms of data also allowed me to comprehensively interpret the online shopping behavior.

I combined thematic (Guest, MacQueen, \& Namey 2012) and abductive (Timmermans and Tavory 2012) analyses. Interestingly, despite the substantial differences in occupation, income level, and life circumstances, the participants used similar terms to describe their interactions with sales staff of physical stores: some salespersons are overly enthusiastic and eager to make a sale, thus creating pressure to make a purchase. Others are aloof and ignore them. Other complaints had to do with bad manners and a lack of professionalism. A common theme emerged from almost all of the interviews: online shopping is a pleasure because it affords more freedom and entails less stress, especially in comparison to the unpredictable customer service in physical stores. Although I asked about shopping experiences in general, many of the respondents referred to incidents during shopping for fashion.

An abductive analysis allows insights from the literature (existing theories), and development of new concepts to account for perplexing empirical findings. Current theoretical justifications for online shopping, such as low prices, are used to formulate tentative analytic frameworks, which validate theoretical establishments based on empirical phenomena, and isolate perplexing events. I then verified the findings against the analytic frameworks and found that most respondents do not cite current theoretical justifications as their main reasons for preferring to shop online. Rather, they referred to "interaction cost" and "FTF interaction as a burden”. Next, I turn to the online shopping habits of the respondents.

\section{Materiality of online shopping in China}


The majority of the customer respondents resoundingly indicated their preference for online shopping. Almost half reported that they logged onto Taobao almost daily, browsed some of the store webpages that they follow (added as favorite stores), and viewed the most recent updates. This differs from the common perception that online shopping is a functional activity for purchasing necessities cheaply (Liu et al. 2008) because many of the respondents do not even compare prices, nor do they buy solely out of necessity.

Compared to real stores, I like online shopping much more. I log onto Taobao almost every day.... If I'm not busy, I buy something almost every day....Many don't require paying for shipping, so I just buy one or two items each time, but I buy very frequently. (Interview 1, female, 26, Changsha, monthly income 10,000 RMB)

Many of the respondents admitted that they do not visit shopping malls anymore. They observed that online shopping has changed consumption patterns in China. ${ }^{8}$ For example, malls in many large cities have been affected and transformed into other uses, such as focusing on dining and children's play areas with shopping taking on a secondary role. ${ }^{9}$

Many indicated that they often purchased unnecessary items. In fact, none perceived Taobao to have the lowest priced products, but this did not deter them from buying online. Certainly, this preference is related to the technological settings of the Taobao websites because they offer regular updates, ease of browsing, "previews" of the items before the auction starts,

\footnotetext{
${ }^{8}$ In this paper, I focus on urban areas. However, Taobao has also changed rural economic and social life, most notably in the "Taobao villages" where many farmers start their business online by selling products from furniture to agricultural products. See Liu et al. (2015).

${ }^{9}$ While this is in line with the general trend of transition from selling goods and services to selling experiences, such as entertainment and educational events (Pine and Gilmore 1998), what is unique in Chinese shopping malls is that the selling of goods, especially those that involve more interaction with salespersons (apparel) have quickly shrunk in recent years.
} 
and occasionally sales or promotion options. The respondents admitted that they frequent Taobao multiple times each day to view recently uploaded information on new items, or read customer reviews to decide whether to make the same purchase. Spending time on Taobao is easy because there are links (and therefore easy access) to other items in the same online shop or similar items in other shops. However, they rarely mention seeking discounted prices as the main reason for shopping on Taobao. Instead, many said that they would only buy from the few shops that are familiar to them (returning customers), even if the price of the same item might be higher than in other online shops.

Indeed, the literature has thoroughly discussed that certain technological settings could lead to addictive behaviors, one being shopping (Schüll 2014; Greenfield, 2011; Chou et al. 2005). The potential for addiction is more likely when repeated interaction reliably produces a desirable outcome, which certainly applies to online shopping. The speed and efficiency of the websites make purchasing easier, and therefore exacerbate the tendency to shop. ${ }^{10}$

However, while the technological design of the shopping website is important in facilitating online shopping, most respondents refer to other reasons that contribute to their preference for online shopping, such as avoiding FTF encounters.

I don't need to interact in person with others online. When shopping in the stores...sometimes the salespeople follow me, or promote stuff, or discriminate [against]

\footnotetext{
${ }^{10}$ Some features of online shopping might make it more likely to be addictive than offline shopping, such as easy access to new item and promotion information; however, other features are counterproductive to addictive behaviors. For example, after making a purchase online, customers need to wait for delivery. Therefore the technology of the online shopping platform itself cannot explain for the addiction to online shopping.
} 
me. But not online.... even if I don't buy anything, it's ok. I feel relaxed and free. (Interview 8, male, 23, Changsha, $5000 \mathrm{RMB}$ )

In fact, roughly $70 \%$ of the interviewees said that they rarely interact with online sales agents during the entire transaction process. They merely viewed the items, made a selection, paid, and then waited for delivery of the item. This is usually called "silent auction" (mopai), which has become increasingly prevalent on Taobao (Alibaba Group, 2016). ${ }^{11}$ Although Aliwangwang conveniently provides instant chatting with online sales agents, most of the respondents only chat when seeking a size recommendation or a return. Mostly, they simply complete the whole transaction process on their own. They consider this easier and more liberating than shopping in physical stores, and feelings of increased ease and freedom when shopping online were mentioned by almost all of the respondents. In physical stores, they must rely on a salesperson as an unwanted intermediary, but the high frequency and open access of shopping online cultivate an unencumbered relationship between customer and product, without sales personnel and lineups. More importantly, they circumvent the power dynamics in FTF interaction, something which I will elaborate upon below.

\section{Escaping the interpersonal power game}

The interviewees pointed out three major differences between online and physical shopping relating to, 1) the amount of information provided to customers, 2) the necessity to put on a status performance, and, 3) the amount of affective labor involved in the shopping process. These three differences are primarily why they prefer to shop online. As well, the primary reason

\footnotetext{
${ }^{11}$ It was believed that bargaining and the capacity for direct interaction on Taobao initially led to its popularity and its competitive advantages over eBay (Barnett et al. 2010). However, this is no longer the case because many online shoppers on Taobao buy through silent auction without any interaction with the online sales agents.
} 
that contributes to these three differences is the lack of FTF encounters with salespersons who are usually migrant workers from rural areas, and according to the urbanite customers, are difficult to work with in the purchase process.

\section{More information available}

The respondents indicated that online shopping provides more information about both the merchandise and the service, either on websites or from other customers on how the merchandise or stores have performed in the past. Salespersons of physical stores are perceived as being incapable of providing comparable reliable information.

\section{More information on merchandise}

In physical stores, customers use their visual and tactile senses to examine products, especially apparel (Ha and Lennon, 2010). However, online shoppers can only rely on provided information, such as written descriptions, which can create uncertainties. Yet the respondents are adamant that more product information is available online.

I think that the product information is more comprehensive and transparent. They post very clear descriptions of their merchandise online. There are also a lot of pictures. I can check and compare (products). But in the stores, there are no similar descriptions. I have to ask the salespeople about product differences. Sometimes they don't even know ... (Interview 12, female, 25, Shanghai, $5000 \mathrm{RMB}$ )

This quote pinpoints a key difference between online and offline shopping: online shopping is a self-sufficient process. In fact, about $70 \%$ of the interviewees indicated that store salespersons know little about products and customer needs, and thus they shop online because it provides more accurate information. 
I went to...buy a fan. I asked the salesperson about the size of one of the fans. She replied, 40 inches...Impossible! I asked if she meant $40 \mathrm{~cm}$, but she insisted 40 inches, and that inch is the same as $\mathrm{cm}$. She is obviously a migrant worker without even a primary school education. I ended up buying the fan online, which had a clear product description... and I didn't have to deal with an illiterate salesperson. (Interview 13, female, 64, Beijing, 20,000 RMB)

This unhappy encounter with a sales clerk in an electronics store stemmed from the ignorance of the sales woman. Many of the other respondents mentioned similar experiences, especially while shopping for fashion items.

...the salesperson would recommend various items...But the clothes are either very ugly, or not a good fit with my job. They're migrant workers from the countryside. What do they know about fashion? But they like to pretend that they know more about fashion than I do, which makes it even more annoying. So I shop online. (Interview 7, female, 42, Beijing, 7000 RMB)

This interviewee thinks that salespersons are poor sources of product information because they are migrants from the countryside, which suggests that they have little education, and are not fashionable. Thus, such status competition creates tension in offline shopping interactions.

Consistent with the findings of $\mathrm{Li}$ (2004) in Taiwan, the respondents also felt more informed online because they could revisit the same website and view the same products multiple times, thereby avoiding the perceived social costs of frequent visits to physical stores. 
...If I go to a store over and over, the salespeople will recognize me. I'd feel very uncomfortable if I didn't buy anything. But it's alright to do that online. This is especially true for prices. I can check online for discounts anytime. But I can't go and ask a salesperson in a real store whether there's a discount every day. It's about face (mianzi). (Interview 2, male, 26, Changsha, $8000 \mathrm{RMB}$ )

This exemplifies another major advantage of online shopping: the avoidance of loss of face if the same store is frequented multiple times without making a purchase.

Many of the respondents also felt that online information is reliable; that is, customer reviews are trustworthy sources of information, despite rumors that online vendors pay for positive reviews and delete negative reviews. They felt that they can differentiate between real and fabricated comments, and instead, considered store sales personnel to have limited and biased knowledge.

In a store, your only information source is the salesperson. For example, if they say, “This air-conditioner is a bestseller", you don't know if that's true or not. But online, it's all clearly documented and very transparent. For example, 30,000 of this type of airconditioner sold in the last three months with 5,000 reviews. That information is more objective and reliable than the salesperson's words. (Interview 30, male, Beijing, 31, 9000 RMB)

The online observations also validate the importance of reviews and comments. The online observations of the reviews and item descriptions validate the feedback from the interview respondents that it is possible to make a judgement about whether clothing fits by reading the item descriptions, such as showing a few models and then stating the size that these models wear. 
In the comments section, other customers also provide information on their own size and whether the clothes fit.

Therefore, like their counterparts in other contexts, these online customers are concerned with "signal credibility, which refers to the honesty of the signals that senders (i.e., the retailers) provide to customers regarding their quality" (Connelly et al. 2011). To them, one of the major benefits of online shopping is that they can obtain more reliable information by reading the comments of other customers. ${ }^{12}$

I think that the reviews are very useful. Take for example, clothing...the photos and customer comments tell you what the clothes are really like...whether the fabric shrinks or fades after washing... which are not available in a real store. (Interview 26, female, 26, Guangzhou, 15,000 RMB)

The reviews written on Taobao differ from those on Amazon. The majority of the Amazon reviews are posted by the top 1000 most active reviewers. Many are written by individuals who did not purchase the items from Amazon (Pinch and Kesler, 2011). However, Taobao users must purchase the item on Taobao to write a review, and only after the entire transaction is completed (auction, shipping, transfer of payment, etc.). Of course, fabricated reviews exist. It was found on Amazon that many rave reviews were written by friends and families, with fake email addresses (Pinch and Kesler 2011). The same is found on Taobao. However, Taobao shoppers already know that, and usually ignore the first couple of reviews

\footnotetext{
${ }^{12}$ Empirical research in other contexts also confirmed that $60 \%$ of the respondents consult online consumer reviews before purchasing a new product or service (Cheung et al. 2015).
} 
(believed to be written by friends of the online vendor owners), confident that they can differentiate fabricated reviews through the rhetoric style.

The respondents felt empowered by the information available to them on Taobao. The Taobao vendors in turn, recognize this edge and offer detailed descriptions of products, fit information, and incentives for customers to submit their feedback and photos of their purchases.

\section{More information on customer service quality}

Online shopping also provides more information on the customer service quality of online stores. Taobao customer reviews tend to focus on the services of the online vendors. On the first page of each online store website, a score is provided which indicates the customer service quality in comparison to other stores on Taobao. In contrast, customers who frequent physical stores usually will not find out about the quality of the customer service until they finish their interaction with the sales personnel. The respondents in this study considered this as another major advantage of shopping online.

The customer service quality is much better in the Taobao stores than the shopping malls. The online sales agents are polite. I guess it's probably because there is a very transparent reviewing system. If the service was bad, the customer would leave a negative review. In a real store, you might have a bad experience, but the next customer won't know about it. But online, everyone can see the negative reviews and avoid that store. Also, the correspondence between a customer and sales agent is recorded (by Aliwangwang). So if a sales agent is rude, s/he might get fired. (Interview 9, male, 27, Shenzhen, 8000 RMB) This information on service quality is so important because almost all of the respondents have had a bad in-store experience. 
When I shop in a real store, I usually end up in a bad mood. Sometimes the way that the salespeople behave makes me mad. Like when the salesperson ignores me. Sometimes they don't even turn their head. (Interview 6, male, 25, Beijing, 6500 RMB)

I went into a store and tried on some clothes. I was going to buy them...but none fit...I said to the sales lady, "I'm sorry. I wasted your time." She said, "Yes, you wasted my time." I got so mad...but this is very common in real stores. (Interview 14, female, 25 , Guangzhou, 10,000 RMB)

According to the interviewees, the poor service is mainly because many of the sales staff are from rural areas and hired without proper training. They do not know how to communicate with customers and lack proper social etiquette or cultural capital. So the customers disrespect them and disregard their advice.

Many of them (sales clerks) start working without any training. The turnover is also very high. So they have no occupational knowledge or skills at all. They don't even know the basics, such as how to talk to customers or basic social etiquette...(Interview 61, female, 54, Beijing, 20,000 RMB)

Given the current urban/rural inequality and discrimination against migrant workers in China (Yi 2011), customers are accustomed to thinking that service providers have a lowly status. Respondents also noted they had more positive experiences with sales staff in other countries, namely in the US and Japan, where good customer service is considered imperative for business (Kang and Ridgway 1996).

The respondents also indicated that they find the sales personnel in physical stores overly aggressive. 
The moment you enter the store, they chase you down and say, "Miss, what do you want to buy?" When you try something on, they look at you and [are] constantly asking, "Would you like to buy this one? You look nice in it"...I don't know why the salespeople in China like to harass their customers... (Interview 57, female, 44, Shanghai, 7000 RMB)

Consequently, the respondents feel pressured to buy without adequate time to browse, examine the items carefully, and make an informed decision.

Yet another problem with physical stores is that the sales personnel are considered to be judgmental and unfriendly.

It's bad enough if they're unapproachable or ignore your questions. But often, they openly show their disdain. Like if you ask them about the price, they respond by saying, "This is expensive; don't touch", or "There's no discount". Sometimes you want to try something on, but they would say, “No, you can't try it on”. (Interview 47, male, 29, Shanghai, $8000 \mathrm{RMB}$ )

Note the contradictory accusations here. That is, the sales staff are both "ignoring" them, but also badgering them to make a purchase. They are unapproachable but also "too eager". They are status conscious (judge certain customers to be unworthy of their time) but status ignorant (migrant workers and "country bumpkins"). This fundamentally demonstrates the discomfort associated with interactions per se; that is, the Chinese urbanites believe that migrants do not know how to be a proper salesperson. Moreover, the urbanites have higher status while the migrants have lower status, a status hierarchy that the migrant workers reject. Therefore, regardless if the migrant salespersons are enthusiastic or aloof, status negotiation makes urbanite customers feel uncomfortable in interactions. 


\section{Less status performance}

Even though some of the respondents insisted that they prefer the tangible products in a physical store, almost all of them indicated a preference for online shopping because they do not need to put on a status performance to demonstrate their purchasing ability. Many of the respondents regarded interaction with store staff as a burden and some even described this burden as an "interaction cost (hu dong cheng ben)". Thus, the lower interaction cost of shopping online is one of its most important advantages because customers do not need to engage in a power struggle with staff. This struggle is related to both the customer service quality in general and the specifics of the encounter. That is to say, each customer might have a very different experience in the same store with the same sales personnel, depending on how s/he acted/performed.

On the other hand, they worry about discrimination in shopping malls or high-end department stores if they do not dress well or perform in a certain way.

I've had bad experiences in malls...if I wear something casual, the salespeople treat me with contempt. They think that I don't have any money. They don't even look at me. So if I need to go to the mall, I'll dress up... and carry a designer purse. (Interview 3, female, 26, Changsha, 8000 RMB)

Many of the other respondents likewise mentioned "discrimination" from sales staff of physical stores because the salesperson would judge their purchasing power, usually by looking at their clothing as soon as they enter the store and conclude that they cannot afford the merchandise. Thus, one of the most important reasons that shopping online is preferred is the lack of judgement or discrimination. 
Similar sentiments were repeatedly expressed by the majority of the respondents, both male and female, and even those who are upper-middle class. For example, one of the respondents with an annual family income of one million RMB, well-educated and worked in Shanghai still felt judged when she went to shop in the malls and had to dress well to avoid poor treatment.

When I went shopping overseas, the relationship between me and the salesperson is service receiver and service provider. If I needed something, they'll find it for me. But in China... first they decide if I can afford to buy their product...then I need to show that I can (afford it). When I ask questions, they answer in a condescending way, so I get defensive. I feel like we're in a constant power struggle. And a lot of energy is wasted doing that. So I just avoid the real stores as much as I can. (Interview 62, female, 31, Hangzhou, 12,000 RMB, emphasis added)

With a monthly income 12,000 RMB in the city of Hangzhou, the purchasing ability of the above respondent is above average. However, she still felt stressed because she felt compelled to take part in a game that demonstrates and defends her status with the salesperson. This phenomenon echoes the finding of Williams (2005: 109), in which “(i)mmediate assumptions were made about customers based on their race, gender, and apparent social class; workers responded to customers using these cues". It is very common for members of an anonymous modern society to rely on visible evidence of life-style such as dress and public displays of possessions such as expensive clothing, to determine social class status (Form and Stone, 1957). Consequently, many of the respondents preferred online shopping because status symbols are less perceptible and therefore status performance is not required. 
The status differences are not that obvious online. In real stores, what you wear and how you act very much affects how the salesperson treats you.... but I'm the customer...so why would I spend money when it makes me feel bad? That's why I prefer online shopping. (Interview 42, male, 35, Shanghai, 15,000 RMB)

The situation is further complicated because many Chinese customers think that salespersons have low social status. When asked to compare his own status with that of the salespersons in Shanghai, one respondent said:

I think that the salespeople have a lower social status. It doesn't matter if they work in a middle- or high-end shop, my status is still higher than theirs because service industry workers don't have job prestige. (Interview 55, male, 30, Shanghai, $7500 \mathrm{RMB}$ )

In Shanghai, the basic monthly salary of a salesperson in a shopping mall is usually $1800 \mathrm{RMB}$. With commission from sales, this increases to approximately $5000 \mathrm{RMB}$, but is still lower than the average wages. Therefore, the source of conflict stems from respondents who want to show their superiority, but the sales staff are unwilling to defer, as is the case with those interviewed in this study.

I believe that people are equal. I don't think that I have to defer to those who have more money. I think we have the same status. I mean, I provide a service and sell the product to them, they pay me to buy the product. In this sense, we're equal. (Interview 21, female, offline store sales agent, monthly income $2200 \mathrm{RMB}$ )

Such status conflicts are caused by status uncertainty, so that there are mismatches between expectations for respect and deference. As discussed earlier, this is related to the socialist legacy of China, in which workers were given dignity. This memory has not faded yet and many 
discourses popular in that era are still propagated by the state and in use today. Therefore, the salespersons draw on a socialist egalitarian discourse to defend their status and dignity. Since service industry work has always been regarded as low status work, Chinese salespersons care very much about their status and dignity over and beyond making a sale or commission. In this study, almost all of the interviewed shop owners and sales agents (both online and offline) indicated unwillingness to sacrifice "dignity" by assuming a subordinate role in exchange for a sale.

If a customer puts on an attitude (acts arrogant), I just ignore him/her. I'd rather lose the sale than lower myself.... my happiness is more important and making money is secondary. I wouldn't waste my time with people who look down on me just for money. If they think that they're paying customers so I have to be at their beck and call, then they're wrong. (Interview 53, female, 21, Wuhan, 4000 RMB, in-store sales (sports apparel))

Thus, it is evident that the interviewees have not exaggerated about their poor shopping experience in the physical shops. Their negative encounters are due to intentionally aggressive or offensive behavior of the sales clerks when they feel that they are belittled or insulted by the customers. Since sales agents prioritize equality during interaction, they treat customers based on how customers act towards them. That is, customers are treated based on whether they respect the sales staff and treat them as equals.

Certainly we treat customers differently. Some are polite and appreciative. But others think that they shop here so you have to treat them like a god. Well, even though I work here, I don't want to put up with that. I'm not going to lower myself. So I ignore them. (Interview 21, offline store sales agent) 
The ambiguity of the relations between customers and sales staff is critical here. Since there are no established norms, the experience of the customer is inherently unpredictable. Sales staff can behave like this because in contrast to the West, there is no consensus yet on who should assume the superordinate or subordinate role during shopping interactions in China. This is consistent with an existing finding by Gould (2003): when status distinctions are less rigid and more ambiguous, conflict is likely to be produced among actors.

Thus with status competition comes along the real possibility of physical assaults in stores in China, which are common incidents as indicated by many of the study respondents. Some of them, especially the female respondents, even felt unsafe because sales clerks have threatened them with physical violence. The source of the conflicts is whether the salesperson accepts the subordinate role during the interaction. In the Chinese context, the salespersons and customers both want to perform the superordinate role, which would not be possible. As Athens (2010: 347) pointed out: "Conflicts over who should perform the super-ordinate and subordinate roles in a social act's construction are ignited when some of the participants' taken-for-granted assumptions about who should dominate the social act's construction are violated".

Everyone sees each other in a real store... so there might be conflicts....customers fight with salespeople. But online, even if the sales agents are cursing you while typing, you don't even know. (Interview 63, female, 33, Hangzhou, 20,000 RMB)

Thus, the respondents consider the lack of FTF interaction online as a major advantage of online shopping because they can avoid the kinds of social contacts that entail status competition and might lead to conflicts. 
In addition to status performance, the respondents showed concern about judgment of their own personal taste and physical appearance. Both the male and female respondents indicated that trying on clothes in physical stores cause them embarrassment and anxiety.

It's hard for me to buy clothes that fit me, especially pants... Sometimes I need to ask (the sales staff) to give me an extra-large size...very embarrassing...but online, I don't have that problem. (Interview 59, female, 27, Shanghai, $9000 \mathrm{RMB}$ )

It's a lot of pressure (shopping in real stores)...there are many... who are trying on the same shirt. They all come out of the fitting-room and stand in front of the mirror. It's embarrassing if you don't look good in it but others do. (Interview 58, male, 30, Shanghai, 22,000 RMB)

Fashion taste is also a concern. More conservatively dressed customers, such as professionals, often encounter sales staff who indicate that their clothing is outdated. In the U.S., salespersons sometimes act as "taste brokers" by providing suggestions on fashion and style but usually respect their customers and give priority to their particular aesthetic sensibility (Sherman 2011). However, since salespersons in China are usually rural migrant workers, they are never considered to be taste brokers. Moreover, since they usually have little professional training in this regard, they can be blunt: "what you wore before is ugly and outdated" (Interview 23, female, 33, Shanghai, 9000 RMB, customer).

In response to the poor treatment from salespeople in physical stores, the respondents seldom challenged them and usually just left because "it's hard to reason with those kinds of people". However, the opposite would hold true if this sort of behavior took place online because physical stores are a space dominated by the salesperson, whereas the online store feels like 
shoppers' own safer space. Second, online conversations are documented, and if needed, records are available to relevant others, such as the store owner. Most importantly, respondents felt that if unprofessional behavior online is challenged, storeowners face repercussions because other customers could access their reviews. However, the same confrontation would have little effect on the reputation of a physical store. Therefore, the respondents felt that their efforts would be futile or even lead to backlash because they would have to address the loss of face, damage to their own reputation, or even a potentially dangerous confrontation.

The salespersons who work in shops that sell fashionable clothing consider themselves to be more knowledgeable about modern fashion, taste, and style and have more experience in those areas. However, since the urbanites tend to consider sales personnel as rural and thus lacking modern qualities, they doubt the ability of these salespersons to make proper recommendations or accurately provide product details. Eventually, this discrepancy, as well as the efforts of the salespersons to pass as urbanites and the urbanites to re-establish social boundaries, lead to unsatisfying encounters. Therefore, it is evident that online shopping is less stressful because there is no status performance or judgement, and fewer opportunities to engage in power struggles with sales agents as there are fewer visible status markers (although there might be other status indicators such as past purchase history).

\section{Less affective labor}

Respondents noted another advantage of online shopping is that the lack of FTF interaction online makes their whole experience, including interactions with sales agents, easier.

On Taobao, I don't need to talk to others in person or I don't know exactly who's talking to me. So it's more relaxing. Even if I challenge the sales agent, it doesn't become 
public.... I can always leave a negative review to express dissatisfaction. But the service is often good. In real stores...(I) have to consider face. For example,... asking about the price.... (then if) I can't afford it, I have to leave. So I've lost face. But online, I can just say no, and nobody cares... (Interview 5, male, 28, Changsha, 5000 RMB)

Evidently, the lack of FTF interaction has a lower interaction cost. Even when sales staff are friendly, there is pressure because customers have the obligation to "pay for their friendliness".

In the stores, you need to consider other's feelings.... Sometimes the sales staff follow you around and show you a lot of things. Then I feel pressured to buy...(otherwise) it's like I wasted their time. Often I've bought things that I didn't want. But online vendors can ....send links about products... answer questions quickly...but I don’t feel pressured to buy.... (Interview 33, male, 29, Shanghai, 11,000 RMB)

These interactions demonstrate how affective labor is fundamentally involved in social exchanges. Reciprocity is one of the most fundamental rules in social exchanges (Blau 1964). Darr and Pinch (2013) pointed out that there is situated constitution of social obligation on the sales floor. More and longer interactions demand more affective labor from the salesperson, and thus increases the obligation of the customer. This holds very true in China. These social obligations are facilitated in physical stores because of the co-presence of people (Darr and Pinch 2013), which do not apply to online shopping and thus contribute to its popularity. All of the respondents reported that they held items in their shopping cart which they may not purchase, or even placed a bid in an auction but not pay for the item without guilt.

Existing studies in retail on customer satisfaction point out that "Responsiveness (a retailer's willingness to help customers and provide prompt response if there is a problem or 
question) is a very important aspect of service quality because it represents a retailer's service attitude" (Hu et al. 2015). However, there are different expectations for online responsiveness. Many may not even engage with online service agents during the whole shopping process, but still consider that online service excels because it is less likely to involve emotions. In contrast, customers need to perform affective labor in physical stores.

When the salesperson smiles at me, or treats me nicely, I feel that I have to respond nicely too.... When they ask, "May I help you?”, it's rude to say, "No, I don't need your help"...if you look at an item and don't buy...Their facial expression changes right away. But online...I have no obligation... I can even turn off my computer to stop the conversation and I don't feel bad at all. (Interview 18, female, 24, Changsha, 4000 RMB)

Consequently, online shopping is preferred because it fosters feelings of ease, relaxation and freedom without the need to navigate the FTF interactions in physical stores.

In the stores, I always need to consider the feelings of other people. Like if I don't buy a lot of things, will the salesperson be unhappy?...But online, I don't have to worry about that. I don't need to pretend that I'm rich...or listen to the sales pitch. I can shop on my own. (Interview 19, female, 27, Shenzhen, 8000 RMB)

Online shopping also easily allows rejection of offers and withdrawal from online interactions.

If I ask a salesperson in a store to show me something but I don't buy it, I feel the need to apologize. But online, even after I've made the order, I can still cancel it. I don't need to apologize. (Interview 43, male, 25, Shenzhen, 6000 RMB)

The respondents also preferred online shopping as they felt more empowered and more in control over the interactional process; starting or ending the process at their leisure without interference 
from sales agents. Therefore, the customer service of online stores does not excel that of the physical stores, but the respondents in this study actually do not need the service at all.

Here, the primary differences are whether there are physical co-presence and visible status signals. During FTF interaction, co-presence is inevitable because of the physical proximity of the actors, but not online (Zhao and Elesh 2008). There is more pressure to put on a status performance and carry out affective labor in physical stores compared to online shopping because of the materiality of the online environment. All these lead to less perceptible status cues, fewer social obligations, and consequently customers feel more empowered.

\section{Conclusion}

Economic exchanges are often considered highly ritualized and largely anonymous transactions, but this does not hold true when shopping in physical stores. However, this is achieved, or at least partly achieved, with online shopping, which, as this study has shown, is why a large number of Chinese customers prefer to shop online. Therefore, FTF interaction could be an obstacle to purchasing, especially in the Chinese context where the rapid market transition and the socialist legacy create a lack of consensus about status hierarchies. While the nouveau riche want respect for their status, the lower social class dismisses them and instead draws on the socialist egalitarian discourse to defend their relative status as equals. In contemporary China, the urban/rural divide takes primacy since customer respondents from a relatively wide range of income categories feel consistently stressed about the interactional process.

The contexts of interactions in physical stores themselves set many of the antecedent conditions that characterize interactions as "stressful". Consequently, the respondents in this 
study feel that less interpersonal interaction is better because dealing with sales staff is exhausting, rather than enjoyable. The lack of consensus about status hierarchy means that actors need to perform and negotiate during a single sales encounter. Therefore, the interaction costs of shopping online are much lower than those of physical stores. Online shopping websites have thus transformed the power dynamics between customers and sales agents during the transaction process.

The interactional process during online shopping is one of the most important reasons for its popularity. Compared with offline shopping, there are feelings of increased power and control, and less uncertainty during the shopping process. There is more information about the vendors, and it is easier to start or end an interaction online. Less emotional energy or affective labor is involved. There are no longer barriers to window shopping or browsing, nor is there a need to engage in FTF interaction with sales staff. Staff are not the only sources of information or means of response to the needs of customers. Status performance is no longer necessary for the cooperation of sales staff, or to find what one needs. Thus, customers do not need to tolerate staff indifference or, worse, insulting remarks. Since online shopping does not require interpersonal interaction, the interpersonal power game prevalent in physical shopping is eliminated (thus, the "silent auction").

The main issues here, then, are face and competition for relative social status during interpersonal interaction. During the shopping process, face is about social class, personal taste, purchasing power, and even physical appearance. Shopping is an interactional process which manifests or constructs the identity or social standing of shoppers. As such, much emotional energy is involved and consumed due to the pressure to gain and give face, both of which require affective labor. Relative status, power, and face during an interactional process are so 
important that the interviewees in this study prefer to shop and browse online to avoid the interpersonal conflicts found in physical stores.

Some of the research findings here are universal, applicable to online shopping in other contexts, such as the lack of physical co-presence online which leads to fewer social obligations and less affective labor. However, some findings are unique to the contemporary Chinese context — or at least to contexts of market transition—-such as the ambiguous status hierarchy and the tendency of salespersons in physical stores to compete for status with customers. Even though these are largely features of a society in transition during which there is the lack of consensus on status, deference and etiquette, the discussions in this paper can help illuminate situations in other contexts where status hierarchy is not clearly defined or perceptible.

The research findings confirm that shopping is much more than an activity that is impelled by economic rationality. There are demonstrations of power and authority, even when there is potential economic loss. However, the conditions that underlie this phenomenon are not known. Under what conditions do people consider economic gains (making a sale) to be more important than interpersonal power? Who is more likely to give precedence to financial gain (when there is an unclear status hierarchy)? These questions provide a framework for future related research.

\section{References:}

Alibaba Group. 2016. Financials and Metrics. Retrieved from http://www.alibabagroup.com/en/ir/financial_fullyear

Athens, Lonnie. 2010. Human Subordination from a Radical Interactionist's Perspective. Journal for the Theory of Social Behaviour 40 (3): 339-368. 
Baidu 2016. Taobao Wang, http://baike.baidu.com/view/1590.htm. Accessed date June 12, 2016

Barnett, William, Luo Xiaoqu, and Feng Mi. 2010. Taobao VS. eBAY china. Unpublished Cases. Graduate School of Business, Stanford University.

Beneito-Montagut, Roser et al. 2017. "Doing Digital Team Ethnography: Being There Together And Digital Social Data". Qualitative Research, vol. 17, no. 6, 2017, pp. 664-682.

Besbris, Max. 2016. Romancing the home: emotions and the interactional creation of demand in the housing market. Socio-Economic Review 14, no. 3: 461-482.

Blau, Peter Michael.1964. Exchange and power in social life. Transaction Publishers.

Brown, Keith R. 2011. Interaction ritual chains and the mobilization of conscientious consumers. Qualitative Sociology 34.1: 121-141.

Bolton, Sharon C., and Houlihan Maeve. 2005. "The (mis) representation of customer service." Work, employment and society 19.4: 685-703.

Cheung, Christy MK, Ivy LB Liu, and Matthew KO Lee. 2015. How online social interactions influence customer information contribution behavior in online social shopping communities: a social learning theory perspective. Journal of the Association for Information Science and Technology 66.12: 2511-2521.

Cho, Jaeho, H. Gil De Zuniga, Hernando Rojas, and Dhavan V. Shah. 2003. Beyond access: The digital divide and Internet uses and gratifications. It \& Society 1.4: 46-72.

Chou, Chien, Linda Condron, and John C. Belland. 2005. A review of the research on Internet addiction. Educational Psychology Review 17.4: 363-388.

CNNIC 2017. The $39^{\text {th }}$ statistical report on Internet development in China. Beijing: China Internet Network Information Center.

Connelly, Brian L., S. Trevis Certo, R. Duane Ireland, and Christopher R. Reutzel. 2011. Signaling theory: A review and assessment. Journal of management 37, no. 1: 39-67.

Darr, Asaf and Trevor Pinch 2013. Performing Sales: Material Scripts and the Social Organization of Obligation. Organization Studies 34(11) 1601-1621.

Davis, Jenny L., and Jurgenson Nathan. 2014. Context collapse: Theorizing context collusions and collisions. Information, Communication \& Society 17(4), 476-485.

Emerson, Richard. M. 1962. Power-dependence relations. American sociological review. 27(1) $31-41$. 
Feagin, Joe R., and Sikes, Melvin P. 1994. Living with racism: The black middle-class experience. Beacon Press.

Fiske, Susan T. 2010. Interpersonal stratification: Status, power, and subordination. Handbook of social psychology.

Form, William H., and Stone Gregory P. 1957. Urbanism, anonymity, and status symbolism. American Journal of Sociology 62.5: 504-514.

Garcia, Angela Cora, Standlee Alecea I., Bechkoff Jennifer and Cui Yan. 2009. Ethnographic Approaches to the Internet and Computer-Mediated Communication. Journal of Contemporary Ethnography 38(1): 52-84.

Goffman, Erving. 1969. The Presentation of Self in Everyday Life. London: Allen Lane.

Gould Roger V. 2003. Collision of Wills: How Ambiguity about Social Rank Breeds Conflict. Chicago: University of Chicago Press.

Granovetter, Mark. S. 1973. The Strength of Weak Ties. American Journal of Sociology 78 (6): 1360-1380.

Greenfield, David. 2011. The addictive properties of Internet usage. Internet addiction: A handbook and guide to evaluation and treatment 135-153.

Guest, Greg, MacQueen Kathleen M., and Namey Emily E. 2012. Applied thematic analysis. Thousand Oaks, California: Sage.

Guo, Jun, and Jaafar Noor Ismawati. 2011. A study on consumers' attitude towards online shopping in China. International Journal of Business and Social Science 2.22:122-132.

Ha, Young, and Lennon Sharron J. 2010. Online visual merchandising (VMD) cues and consumer pleasure and arousal: Purchasing versus browsing situation. Psychology \& Marketing 27.2: 141165 .

Hahl, Oliver, and Zuckerman Ezra W. 2014. The denigration of heroes? how the status attainment process shapes attributions of considerateness and authenticity. American Journal of Sociology 120(2), 504-554.

Hallett, Ronald E., and Kristen Barber. 2014. Ethnographic Research In A Cyber Era. Journal of Contemporary Ethnography, vol. 43, no. 3, 2013, pp. 306-30. SAGE Publications.

Han, Yanmin. 2007. Consumer online shopping intentions for multi-SEM model. Statistics and Decision 2007(4): 9-11. 
Hanser, Amy. 2010. Uncertainty and the problem of value: Consumers, culture and inequality in urban China. Journal of Consumer Culture, 10(3), 307-332.

Hoffman, Lisa. 2006. Autonomous choices and patriotic professionalism: On governmentality in late-socialist China, Economy and Society, 35:4, 550-570

Homans, George C. 1961. Social Behavior: Its Elementary Forms. Harcourt, Brace \& World, New York.

Honneth, Axel. 1996. The Struggle for Recognition: The Moral Grammar of Social Conflicts. Cambridge, Mass. MIT Press.

Horrigan, John A. 2008. Online shopping. Pew Internet \& American Life Project Report 36, 1-24.

Høybye, Mette Terp. 2016. Engaging the Social Texture of Internet Cancer Support Groups. Journal of Contemporary Ethnography, vol. 45, no. 4, pp. 451-473.

Hu, Mingyao, Rabinovich Elliot, and Hou Hanping. 2015. Customer Complaints in Online Shopping. Journal of Electronic Commerce Research 16(2), 95-108

Johns Nick, Andrew Chan, and Hanny Yeung. 2003. The impact of Chinese culture on service predisposition." The Service Indsutries Journal 23.5: 107-122.

Kalkhoff, Will and Thye Shane R. 2006. Expectation states theory and research: New observations from meta-analysis. Sociological Methods and Research 35(2): 219-249.

Kalkhoff, Will, Younts Wesley C., and Troyer Lisa. 2008. Facts \& artifacts in research: The case of communication medium, gender, and influence. Social Science Research 37.3: 1008-1021.

Kang, Yong-Soon, and Ridgway Nancy M. 1996. The importance of consumer market interactions as a form of social support for elderly consumers. Journal of Public Policy \& Marketing: 108-117.

Knorr Cetina, Karin D. 2005. How are global markets global? The architecture of a flow world. In Knorr Cetina, Karin, and Alex Preda. 2006. The sociology of financial markets (pp. 38-62). Oxford: Oxford University Press.

Koyuncu, Cuneyt, and Bhattacharya Gautam. 2004. The impacts of quickness, price, and payment risk, and delivery issues on on-line shopping. Journal of Socio-Economics 33(2): 241-251.

Lee, Ching Kwan. 2000. “The 'Revenge of History': Collective Memories and Labor Protests in North-eastern China”. Ethnography 1(2), 217-237.

Leifer, Eric, and Rajah Valli. 2000. Getting Observations: Strategic Ambiguities in Social Interaction. Soziale Systeme 6, H. 2, 251-267. 
$\mathrm{Li}$, Shu-Chu Sarrina. 2004. Examining the factors that influence the intentions to adopt internet shopping and cable television shopping in Taiwan. New Media \& Society 6(2), 173-193.

Liang, Bo, Tu Yanbin, Thomas Cline, and Ma Zhongyu. 2016. "China's E-Tailing Blossom: A Case Study." In E-Retailing Challenges and Opportunities in the Global Marketplace, pp. 72-98. IGI Global

Lissitsa, Sabina, and Kol Ofrit. 2016. Generation X vs. Generation Y-A decade of online shopping. Journal of Retailing and Consumer Services 31, 304-312.

Liu, Changyu, Li, Jiale, and Liu, Jing. 2015. Rural E-commerce and New Rural Business Model: A Case Study of "Taobao Village" in Jiangsu Province. Asian Agricultural Research, 07, Asian Agricultural Research, November 2015, Vol.07.

Liu, Xia, He Mengqiao, Gao Fang, and Xie Peihong. 2008. An empirical study of online shopping customer satisfaction in China: a holistic perspective. International Journal of Retail \& Distribution Management 36(11):919-940.

Marx, Karl, and Engels Friedrich. 1932/1998. The German Ideology. Amherst, NY: Prometheus Books.

Menchik, Daniel A., and Tian Xiaoli. 2008. Putting social context into text: The semiotics of email interaction. American Journal of Sociology 114.2 : 332-370.

Murthy, Dhiraj. 2008. Digital ethnography: An examination of the use of new technologies for social research." Sociology 42.5: 837-855.

Murphy, Rachel. 2004. Turning Peasants into Modern Chinese Citizens: "Population Quality" Discourse, Demographic Transition and Primary Education. The China Quarterly 177: 1-20.

Nee, Victor, and Opper Sonja. 2012. Capitalism from Below: Markets and Institutional Change in China. Cambridge: Harvard University Press.

Palmer, David (Forthcoming). "Three Moral Codes and Micro-Civil Spheres in China". The Civil Sphere in East Asia and Breeching the Civil Order: Radicalism and the Civil Sphere. Edited by Jeffrey Alexander, David Palmer, Agnes Ku and Sunwoong Park. Cambridge University Press.

Park, Robert. 1925. The Urban Community as a Spatial Pattern and Moral Order. Pp. 165-177 in Human Communities, edited by Everett Hughes. New York: The Free Press.

Park, Robert. and Burgess Ernest Watson. 1924. Introduction to the Science of Sociology. Chicago, IL: University of Chicago Press. 
Parsons, Talcott. 1940. An analytical approach to the theory of social stratification. American Journal of Sociology 45(6), 841-862.

Pinch, Trevor, and Kesler Filip. 2011. "How aunt Ammy gets her free lunch: A study of the topthousand customer reviewers at amazon. com." https://www.truthinadvertising.org/wpcontent/uploads/2013/11/HowAuntAmmyGetsHerFreeLunch-FINAL.pdf

Pine, B. Joseph, and James H. Gilmore.1998. Welcome to the experience economy. Harvard business review 76 (1998): 97-105.

Podolny, Joel M. 2005. Status Signals: A Sociological Study of Market Competition. Princeton University Press, Princeton, NJ.

Ridgeway, Cecilia L., Kristen Backor, Yan E. Li, Justine E. Tinkler, and Kristan G. Erickson. 2009. How easily does a social difference become a status distinction? Gender matters. American Sociological Review 74(1) 44-62.

Robinson, Laura, and Schulz Jeremy. 2009. New Avenues for Sociological Inquiry: Evolving Forms of Ethnographic Practice. Sociology 43:685-98.

Rohm, Andrew J., and Swaminathan Vanitha. 2004. A typology of online shoppers based on shopping motivations. Journal of Business Research 57, 748-757.

Schoolman, Ethan D. 2016. Completing the Circuit: Routine, Reflection, and Ethical Consumption. Sociological Forum 31(3): 619-641.

Schüll, Natasha Dow. 2014. Addiction by design: Machine gambling in Las Vegas. Princeton University Press

Sherman, Rachel. 2011. The Production of Distinctions: Class, Gender, and Taste Work in the Lifestyle Management Industry. Qualitative Sociology 34(1), 201-219.

Simmel, Georg. 1950. The Sociology of Georg Simmel. Edited and introduced by Kurt Wolf. New York: Free Press.

Singh, Jasjit, Hansen Morten T., and Podolny Joel M. 2010. The world is not small for everyone: Inequity in searching for knowledge in organizations. Management Science 56(9), 1415-1438.

Stone, Gregory P. 1954. City Shoppers and Urban Identification: Observations on the Social Psychology of City Life. American Journal of Sociology 60 (1), 36-45.

$\mathrm{Su}$, Dan, and Xu Huang. 2011. Research on Online Shopping Intention of Undergraduate Consumer in China--Based on the Theory of Planned Behavior. International Business Research 4(1): 86-92. 
Sussman, Nan M., and Tyson Dianne H. 2000. Sex and power: Gender differences in computermediated interactions. Computers in Human Behavior 16(4), 381-394.

Sutphin, Suzanne Taylor, and Simpson Brent. 2009. The role of self-evaluations in legitimizing social inequality. Social Science Research 38(3), 609-621.

The United Nations Conference of Trade and Development. 2015. Information Economy Report 2015. https://www.digitalcommerce360.com/2015/03/31/number-global-online-shoppers-willgrow-50-2018/

Tian, Xiaoli, and Menchik Daniel A. 2016. On violating one's own privacy: N-adic utterances and inadvertent disclosures in online venues. Studies in Media and Communications 11, 3-30.

Tian, Xiaoli. 2016. Network Domains in Social Networking Sites: Expectations, Meanings, and Social Capital. Information, Communication \& Society. 19 (2): 188-202.

Tian, Xiaoli. 2017. Embodied versus disembodied information: How online artifacts influence offline interpersonal interaction. Symbolic Interaction. 40 (2): 190-211.

Tian, Xiaoli. 2017. Embodied versus disembodied information: How online artifacts influence offline interpersonal interaction. Symbolic Interaction Online first: http://onlinelibrary.wiley.com/doi/10.1002/symb.278/full

Timmermans, Stefan, and Tavory Iddo. 2012. Theory construction in qualitative research from grounded theory to abductive analysis. Sociological Theory 30(3):167-186.

Travers, Ann. 2000. Writing the Public in Cyberspace: Redefining Inclusion on the Net. New York: Garland.

Tong Xin. 2005.The Cultural Basis of Workers' Collective Action in a Transitional State-Owned Enterprise During a Time of Transition, Chinese Sociology \& Anthropology, 38:1, $42-70$

Tyler, Tom R., and Blader Steven L.2003. The group engagement model: Procedural justice, social identity, and cooperative behavior. Personality and social psychology review 7(4) 349361.

Walder, Andrew G. 1996. Markets and inequality in transitional economies: Toward testable theories. American Journal of Sociology 101 (4), 1060-1073.

Walstrom, Mary K. 2004a. Ethics and engagement in communication researchership: Analyzing public, online support groups as researcher/participant-experiencer. In Virtual research ethics: Issues and controversies, edited by E. A. Buchanan, 174-202. Hershey, PA: Information Science Publishing. 
. 2004b. "Seeing and sensing" online interaction: An interpretive interactionist approach to USENET support group research. In Online social research: Methods, issues, \& ethics, edited by M. D. Johns, S.-L. S. Chen, and G. J. Hall, 81-97. New York: Peter Lang.

Whyte, Martin King.2010. The Paradox of Rural-Urban Inequality in Contemporary China. Pp. 1-25 One Country, Two Societies: Rural-Urban Inequality in Contemporary China, edited by Martin King Whyte. Cambridge, MA: Harvard University Press.

Williams, Christine L. 2005. Shopping as Symbolic Interaction: Race, Class, and Gender in the Toy Store. Symbolic Interaction 28(4), 459-472.

Wrigley, Julia. 1995. Other People's Children. New York: Basic Books.

Wu, Xiaogang and Treiman Donald J. 2007. Inequality and Equality under Chinese Socialism: The Hukou System and Intergenerational Occupational Mobility. American Journal of Sociology 113(2):415-45

Yi, Lin. 2011. Turning Rurality into Modernity: Suzhi Education in a Suburban Public School of Migrant Children in Xiamen. The China Quarterly 206:313-29.

Yu, LiAnne. 2014. Consumption in China: How China's New Consumer Ideology is Shaping the Nation. Polity Press.

Yoon, Cheolho. 2009. The effects of national culture values on consumer acceptance of ecommerce: Online shoppers in China. Information \& Management 46 (5): 294-301.

Zhao, Shanyang, and Elesh David. 2008. Copresence as 'Being with': Social contact in online public domains. Information, Communication \& Society 11(4), 565-583.

Zhang, Weiwei. 2017. No Cultural Revolution? Continuity and Change in Consumption Patterns in Contemporary China. Journal of Consumer Culture 17.3: 639-658.

Zillien, Nicole, and Hargittai Eszter. 2009. Digital distinction: Status-specific types of internet usage. Social Science Quarterly 90(2), 274-291.

Zukin, Sharon, and Maguire Smith Jennifer. 2004. Consumers and consumption. Annual Review of Sociology 30, 173-197. 